\title{
Prune belly sequence in a non-identical twin
}

\author{
Ramnik V Patel, ${ }^{1,2}$ David Marshall, ${ }^{3}$ David Millar, ${ }^{4}$ Mary O'connor ${ }^{5}$
}

1 Department of Paediatric Urology, University College London Hospitals NHS

Foundation Trust, London, UK ${ }^{2}$ Department of Paediatric

Urology, Great Ormond Street Children Hospital NHS Trust, London, UK

${ }^{3}$ Department of Paediatric Surgery, The Royal Belfast Hospital for Sick Children, Belfast, UK

${ }^{4}$ Department of Neonatology, The Royal Belfast Hospital for Sick Children, Belfast, UK ${ }^{5}$ Department of Paediatrics, The Royal Belfast Hospital for Sick Children, Belfast, UK

\section{Correspondence to}

Ramnik V Patel,

ramnik@doctors.org.uk

Accepted 30 May 2014

\section{DESCRIPTION}

Twin 1 of dichorionic diamniotic twins weighing $3670 \mathrm{~g}$ was born by elective caesarean section at $37+4$ weeks gestation. Antenatal diagnosis of bilateral gross hydroureteronephrosis without bladder wall thickening and absence of key hole sign on prenatal ultrasound scans suggested a possibility of the prune belly sequence. The other twin had no anomalies detected. Initial 10 week gestational scan showed the changes and $18+3$ week scan showed reduced amniotic fluid volume as well. At $26+3$ week scan urinary ascites was noted in addition. Fetal echocardiogram and chromosomes were normal. Following delivery the twin needed continuous positive airway pressure in the delivery suite followed by oxygen but was on room air within hours of birth. At birth the twin was noted to have grossly distended abdomen with wrinkled skin and visible dilated ureters and kidneys and has bilateral undescended testes suggestive of prune belly sequence (figure 1A). The complete blood count, liver functions and electrolytes were normal but urea was 6.7 and creatinine 139 . Ultrasound scan showed bilateral gross hydroureteronephrosis with normal thickness of the bladder wall and no key hole sign (figure 1B). Micturating cystourethrogram showed bilateral vesicoureteral reflux, smooth large capacity bladder with mild dilation of the posterior urethra but no valves and large postmicturition residue in the bladder (figure 1C). The twin was treated conservatively with prophylactic antibiotic cover and his renal function improved to normal. The twin is thriving well and asymptomatic at 3 months follow-up. Prune belly sequence in one of the twins is rare, most males are infertile and prenatal diagnosis is possible. ${ }^{1-3}$ Our case will need dialysis in the medium term and renal replacement in the longer term.

\section{Learning points}

- Prune belly sequence, triad, Eagle Barrett or abdominal muscle deficiency syndrome is a rare congenital disorder (1 in 35-50 000) exclusively seen in males $(20: 1)$ and characterised by a triad of wrinkled abdominal skin with abdominal wall muscle deficiency, undescended testis and dilated urinary tract.

- Prenatal diagnosis is possible with dilated upper urinary tract without bladder wall thickness and absence of key hole sign.

- It is important to avoid infection and establish free drainage of the urinary tract. Prognostically there are three groups-group 1 is the most severely affected and early death is inevitable; group 2 ill as neonates; high diversion is often required and later reconstruction may be possible and group 3 healthy as neonates and little reconstructive surgery is required.

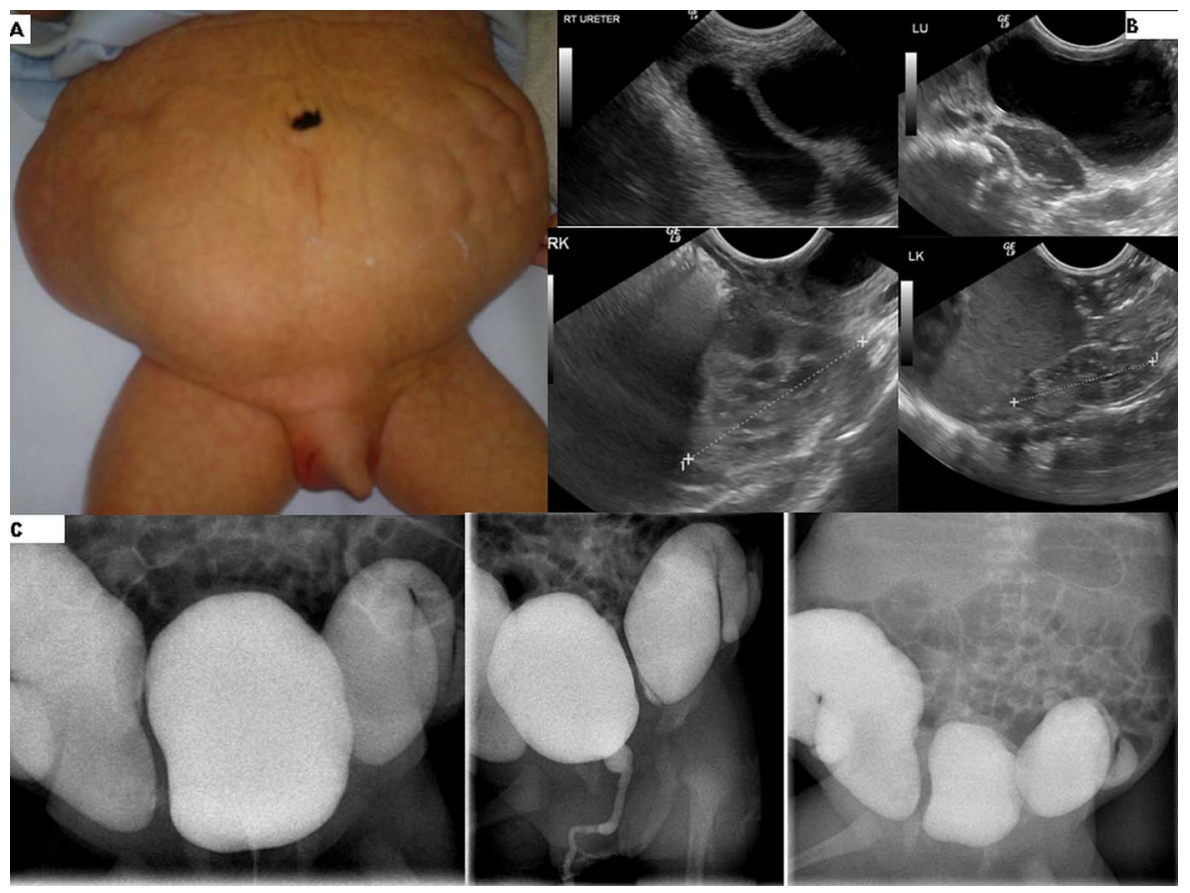

Figure 1 (A) Clinical photograph showing wrinkled abdominal skin with deficient abdominal wall muscles through which dilated ureters and kidneys are seen with undescended testis (Triad). (B) Ultrasound scan showing both dilated ureters and kidneys. (C) Filling, voiding and postmicturition phase of micturating cystourethrogram. 
Competing interests None.

Patient consent Obtained.

Provenance and peer review Not commissioned; externally peer reviewed.

\section{REFERENCES}

1 Vani A, Saritha S, Sangeetha $K$, et al. Prune belly syndrome (sequenze): a case report. Int J Res Med Sci 2013;1:148-52.
2 Hillman RT, Garabedian MJ, Wallerstein RJ. Pregnancy outcome in a woman with prune belly syndrome. BMJ Case Rep 2012;2012:pii:

bcr-2012-006490.

3 Papantoniou N, Papoutsis D, Daskalakis G, et al. Prenatal diagnosis of prune-belly syndrome at 13 weeks of gestation: case report and review of literature. J Matern Fetal Neonatal Med 2010;23:1263-7.

Copyright 2014 BMJ Publishing Group. All rights reserved. For permission to reuse any of this content visit http://group.bmj.com/group/rights-licensing/permissions.

BMJ Case Report Fellows may re-use this article for personal use and teaching without any further permission.

Become a Fellow of BMJ Case Reports today and you can:

- Submit as many cases as you like

- Enjoy fast sympathetic peer review and rapid publication of accepted articles

- Access all the published articles

- Re-use any of the published material for personal use and teaching without further permission

For information on Institutional Fellowships contact consortiasales@bmjgroup.com

Visit casereports.bmj.com for more articles like this and to become a Fellow 